\title{
EXPERIMENTAL STUDIES OF THE NUCLEAR-PHYSICAL CHARACTERISTICS OF THE EXTENDED URANIUM TARGET IRRADIATED BY RELATIVISTIC PROTONS, DEUTRONS AND ${ }^{12}$ C NUCLEI
}

\author{
A.A. Zhadan', V.V.Sotnikov ${ }^{1}$, V.A. Voronko', A.A. Baldin' ${ }^{2}$ S.I. Tyutyunnikov ${ }^{2}$, O.V. Bukhal, \\ K.V. Husak, I.V.Zhuk, P. Zhivkov ${ }^{3}$ \\ ${ }^{1}$ National Science Center "Kharkov Institute of Physics and Technology”, Kharkiv, Ukraine; \\ ${ }^{2}$ Joint Institute for Nuclear Research, Dubna, Russia; \\ ${ }^{3}$ Joint Institute for Power and Nuclear Research - SOSNY, Minsk, Belarus; \\ ${ }^{4}$ Institute for Nuclear Research and Nuclear Energy, Sofia, Bulgaria \\ E-mail: zhadan@kipt.kharkov.ua
}

In 2011-2017 in the framework of the international collaboration project "Energy and Transmutation of RAW", a series of experimental studies on the deep subcritical uranium assembly QUINTA were carried out. The massive uranium target ( $512 \mathrm{~kg}$ of ${ }^{\text {nat }} \mathrm{U}$ ) was irradiated with $0.66 \mathrm{GeV}$ proton, deuterons and ${ }^{12} \mathrm{C}$ nuclei (1 to $\left.4 \mathrm{AGeV}\right)$ from the Phasotron and Nuclotron accelerators (JINR, Dubna). The main results of experimental studies carried out with the participation of the Kharkov group of collaboration are presented.

PACS: 28.41. Kw, 28.50. Ft

\section{INTRODUCTION}

The increased in the past two decades interest in the study of subcritical accelerator-driven systems (ADS) for the purpose of using them to solve applied problems led to theoretical and experimental studies in this field in the world's leading nuclear centers. At the present time the powerful multipurpose accelerator centers such as SNS, USA ( 1.3 MW power) [1], J-PARC, Japan $(\sim 1 \mathrm{MW})$ [2], the PSI, Switzerland ( 0.75 MW) [3] have been operated. They have different departments in structure that study materials, transmutation of radioactive waste, medical radioisotopes production, etc. These centers use proton accelerators with energies of about $1 \mathrm{GeV}$ (or less) for neutron generation. Mean while, a number of experiments have studied neutron production in thick targets (JINR, LANL, KEK, and ITEP), and found that more energy accelerator should be used for more effective neutron generation. In particular, the group of V. Yurevich (JINR, Dubna) performed the cycle of experimental studies [4, 5] and analysis of available experimental data of neutron energy spectra that produced in thick targets. It was shown that for thick targets secondary nuclear interactions in the target give additional contribution to neutron emission. Neutron multiplication with simultaneous weakening of the charged particle release makes thick target, especially as neutron sources. The ratio of total energy expended on the neutron formation to particle beam energy shows weak growth with beam energy and does not depend on type of particle primary beam. The effect of average neutron energy increasing per unit of beam energy with increasing of beam energy has also been noted. That could be used for further neutron multiplication when using a quasi-infinite target. In this context, a more efficient use of beam energy for neutron production will significantly increase the value of optimum beam particle energy.

Within the framework of the international project "Energy and Transmutation of RAW" a series of experiments aimed at the new ADS concept (relativistic nuclear technology - RNT [6]) verification was carried out in 2011-2017 at the Nuclotron and Phasotron accelerators (JINR, Dubna).

The basic physical idea of this approach is to use natural (depleted) uranium or thorium to create an ADS with a deep subcritical quasi-infinite (with negligible neutron leakage) multiplying target irradiated with protons, deuterons, or light nuclei with energy in the range $1 \ldots 5 \mathrm{AGeV}$ and possibly higher. Such scheme can provide extremely hard neutron spectrum within the subcritical active core and ensure an effective burning of core material as well as spent nuclear fuel added to the initial core.

The experiments ("Energy and Transmutation of RAW") were carried out with a target assembly (TA) Quinta [6] which containing $512 \mathrm{~kg}$ of natural uranium surrounded by a lead shield. Schematic drawing of Quinta setup is presented on Fig. 1. The TA Quinta was irradiated with $0.66 \mathrm{GeV}$ protons, and deuterons and carbon ions with energy in the range $1 \ldots 4 \mathrm{AGeV}$.

In this work the main results of experimental studies carried out with the participation of the Kharkov group of collaboration are presented.

In our experiments [7 - 15], spatial distributions of the ${ }^{239} \mathrm{Pu}$ production rates and ${ }^{238} \mathrm{U}$ fission were studied, and the ${ }^{238} \mathrm{U}$ fission total number and ${ }^{239} \mathrm{Pu}$ production in the volume of the uranium target was estimated; experimental dependences of the total number of uranium fission and accumulated ${ }^{239} \mathrm{Pu}$ on the energy and type of the primary beam particles were obtained; the spatial distributions of ${ }^{59} \mathrm{Co}(n, x)$ reaction rates in a wide range of threshold energies from 0 to $70 \mathrm{MeV}$ were investigated; the beam power gains were obtained and these values were extrapolated for a quasi-infinite uranium target; the reaction rates of the minor actinides transmutation in the neutron spectra of the uranium target have been studied. The obtained experimental results were compared with model calculations.

\section{EXPERIMENT AND METHODS}

The uranium target of the TA Quinta (see Fig. 1) consists of 5 hexagonal sections (114 $\mathrm{mm}$ in length, 
$350 \mathrm{~mm}$ in height) filled with metallic natural uranium cylindrical rods. The total mass of uranium in 5 sections of the target is $\approx 512 \mathrm{~kg}$. The uranium fill factor is about 0.6. Quinta is a deep subcritical assembly with $k_{\text {eff }} \approx 0.22$. The uranium target is placed inside $10 \mathrm{~cm}$ thick lead blanket.

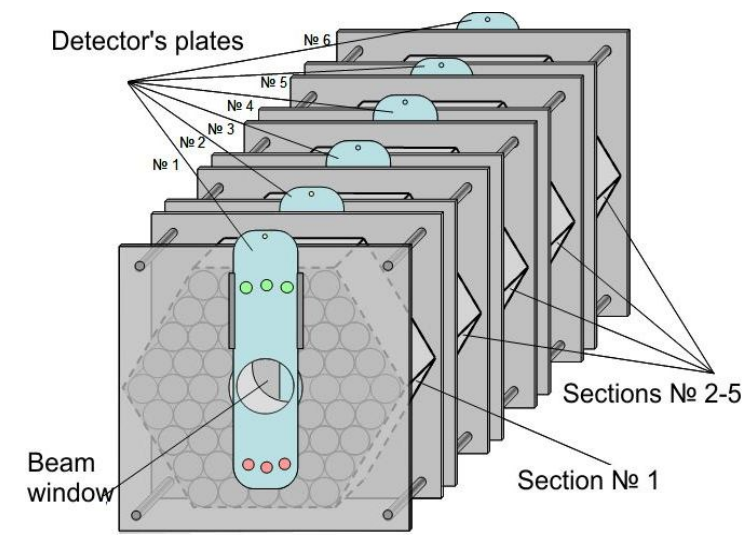

Fig. 1. Uranium target QUINTA with detector plates. The natural uranium mass for each section $-104.92 \mathrm{~kg}$

Before, between and behind of the uranium target sections in $17 \mathrm{~mm}$ gaps, detector plates are mounted. On these plates the various types of activation and track detectors are placed. For more detailed description of TA Quinta and detectors location, see $[8,13]$.

The uranium target was irradiated with $0.66 \mathrm{GeV}$ protons, 1, 2, 4, and $8 \mathrm{GeV}$ deuteron and with 24 and $48 \mathrm{GeV}$ carbon beams from the Nuclotron and Phasotron accelerators of the JINR. The total number of protons, deuterons and ${ }^{12} \mathrm{C}$ ions to hit the target was determined from the activation of $\mathrm{Al}$ and $\mathrm{Cu}$ foils in the ${ }^{27} \mathrm{Al}(a, x)^{24} \mathrm{Na}$ and ${ }^{\text {nat }} \mathrm{Cu}(a, x)^{24} \mathrm{Na}$ reaction. Detailed information of the beam monitoring is published in [18, 19]. The beam shape and beam positioning on the target were determined using the track detector technique [17].

To determine the spatial neutron flux distribution and the reactions caused by them in the volume of the uranium target various types of the activation and track detectors have been used.

After the end of irradiation, the activation detectors taken out from the target to measure $\gamma$-spectra using HPGe detectors. Detection efficiency curves of detectors for various measurement positions were constructed using the following standard gamma sources: ${ }^{54} \mathrm{Mn}$, $57 \mathrm{Co},{ }^{60} \mathrm{Co},{ }^{88} \mathrm{Y},{ }^{109} \mathrm{Cd},{ }^{113} \mathrm{Sn},{ }^{133} \mathrm{Ba},{ }^{137} \mathrm{Cs},{ }^{139} \mathrm{Ce},{ }^{152} \mathrm{Eu}$, ${ }^{228} \mathrm{Th}$, and ${ }^{241} \mathrm{Am}$.

For ${ }^{238} \mathrm{U}(\mathrm{n}, \gamma)$ and ${ }^{\text {nat }} \mathrm{U}(\mathrm{n}, \mathrm{f})$ reaction rate measurements the activation detectors from natural metallic uranium (diameter $8 \mathrm{~mm}$, thickness $1 \mathrm{~mm}$, mass $\sim 0.9 \mathrm{~g}$ ) were used. In each irradiation 29 activation detectors were used. These detectors were mounted onto six removable detector plates (see Fig. 1) at $0,4,8$, and $12 \mathrm{~cm}$ $(\mathrm{R})$ from target axis $(Z)$.

The number of neutron radiation capture reactions was determined by the yield of $\gamma$-line with $277.6 \mathrm{keV}$ accompanying ${ }^{239} \mathrm{~Np}$ decay:

$$
{ }^{238} \mathrm{U}(\mathrm{n}, \gamma){ }^{239} \mathrm{U}\left(\beta^{-} 23.5 \mathrm{~m}\right) \rightarrow{ }^{239} \mathrm{~Np}\left(\beta^{-} 2,4 \mathrm{~d}\right) \rightarrow{ }^{239} \mathrm{Pu} \text {. }
$$

Fissions reaction rates were determined by yield of gamma-lines $743.4,364.5,529.9$ (87\%), and $293.3 \mathrm{keV}$ which accompany decay of fission products ${ }^{97} \mathrm{Zr},{ }^{131} \mathrm{I}$,
${ }^{133} \mathrm{I}$, and ${ }^{143} \mathrm{Ce}$ respectively. Cumulative yields (CY) of these masses of products not greatly changed in a wide range of neutron energies (see more detail ref. [13]). We used the following values of $\mathrm{CY}:{ }^{97} \mathrm{Zr}-5.4 \%,{ }^{131} \mathrm{I}-$ $3.6 \%,{ }^{133} \mathrm{I}-6.4 \%,{ }^{143} \mathrm{Ce}-4.3 \%$ (average evaluated data for fission spectrum and $14 \mathrm{MeV}$ neutrons). Fission rates obtained for ${ }^{97} \mathrm{Zr},{ }^{131} \mathrm{I},{ }^{133} \mathrm{I}$, and ${ }^{143} \mathrm{Ce}$ are averaged.

The overall uncertainties of the reaction rates obtained through gamma spectroscopy method are $12 . .15 \%$, mainly due to errors in cross-section of monitor reactions.

\section{MONTE CARLO SIMULATIONS}

The irradiation of the Quinta assembly was simulated using MCNPX 2.7 code [20]. The INCL4-ABLA physics model and LAQGSM code were used. The neutron and charge particle spectrum at the location of irradiated samples was calculated and then the convolution with cross-sections from ENDF/B-VII evaluation [21] and from TENDL-2014 [22]. In the simulation the detailed geometric model of the target QUINTA and experimental data about beam shape and position on the target were employed.

\section{RESULTS AND DISCUSSION 3.1. SPATIAL DISTRIBUTION AND TOTAL
NUMBER OF FUSSION AND CAPTURE REACTIONS}

Fig. 2 shows the experimental axial distribution of ${ }^{n a t} \mathrm{U}$ fission rates for deuteron and ${ }^{12} \mathrm{C}$ ion primary beams with various energies. Value of reaction rates normalized per one gram of ${ }^{\text {nat }} \mathrm{U}$, per one incident particle and per $1 \mathrm{GeV}$ particle energy.

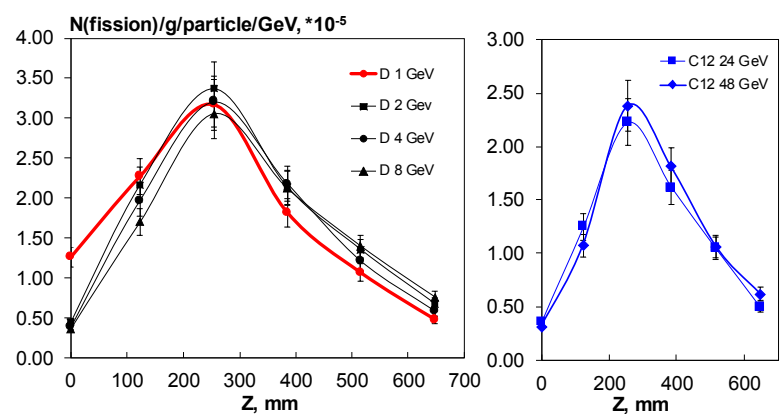

Fig. 2. Axial distributions of ${ }^{n a t} U(n, f)$ reaction rates average over radial distribution at each detector plate

For this normalization, the distributions of reaction rates of one type of primary particles are close together for all beam energies. But one can see that with increasing beam energy, a relative decrease in the number of reactions at the first half of the target is observed in the axial distributions of uranium fission events, and a slight increase in these quantities is observed at the same time at the second half of the target along the direction of the primary beam.

Axial distributions of capture reaction rates are similar to axial distributions of fission reaction rates.

Based on spatial distributions of neutron capture and fissions reactions (both for experimental values and simulated using MCNPX 2.7) the total number of ${ }^{239} \mathrm{Pu}$ production and the total number of ${ }^{\text {nat }} U$ fissions were obtained in the volume of uranium target (Figs. 3 and 
4). Estimation of these values was carried out in the approximation of the cylindrical target with a radius $\mathrm{R}=140 \mathrm{~mm}$ (inscribed circle radius of uranium sections). The radial distance between the activation detectors and the primary beam axis calculated taking into account beam position at the front end of the target.

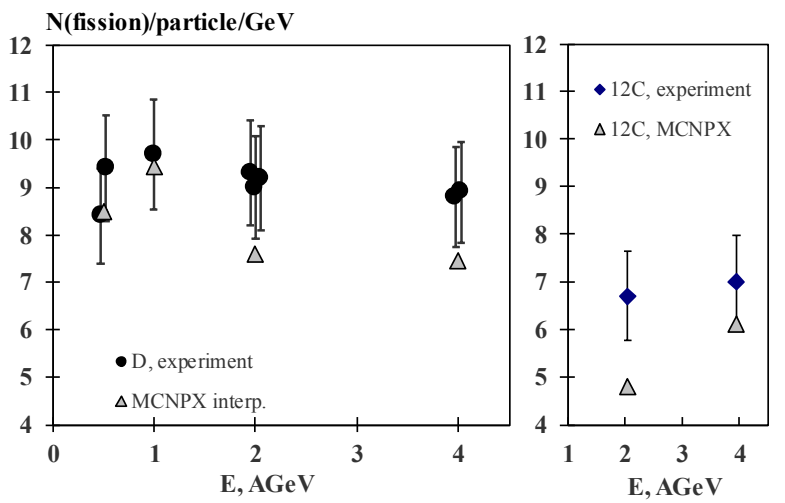

Fig. 3. Integral numbers of ${ }^{\text {nat }} U(n, f)$ reactions in the volume of uranium target as a function of beam energy $\mathrm{N}$ (capture)/particle/GeV
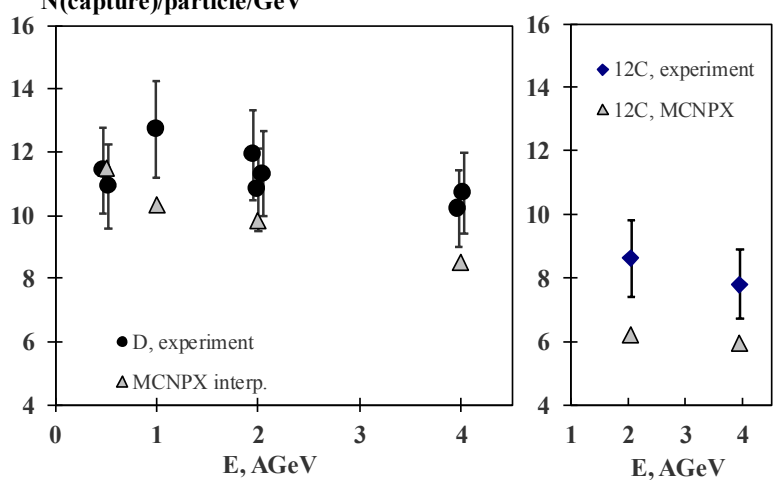

Fig. 4. Integral numbers of ${ }^{238} U(n, \gamma)$ reactions in the volume of uranium target as a function of beam energy

The integral number of fissions reactions $\left(\mathrm{N}_{\mathrm{f}}\right)$ in the volume of uranium target of QUINTA, that was obtained by means of gamma spectroscopy, remains approximately constant within our $14 \%$ of the experimental errors for $1,2,4$, and $8 \mathrm{GeV}$ deuteron (per a deuteron and per $1 \mathrm{GeV}$ energy of the beam or per unit of primary beam power). The integral number of fission reactions for carbon beams is smaller than for deuteron beams by $20 \ldots 25 \%$.

For the integral number of capture reactions $\left(\mathrm{N}_{\mathrm{c}}\right)$ we have seen maximum at $2 \mathrm{GeV}$ ( $1 \mathrm{GeV}$ per nucleon) for deuteron beam. With a further increase in the beam energy, the $\mathrm{N}_{\mathrm{c}}$ values decrease.

MCNPX code simulation of integral number of fissions and capture reactions is in agreement with the experimental data in the range of $20 \%$. In case of carbon beam, we have $35 \%$ deviation between experimental and simulated data.

Another discrepancy between the experiment and the Monte Carlo calculation is shown in Fig. 5. Fig. 5 shows the axial distribution of ${ }^{\text {nat }} U$ fission rates for six uranium samples at $\mathrm{R}=8 \mathrm{~cm}$. As can be seen in the case of the $2 \mathrm{GeV}$ deuteron beam there is a good agreement between the calculation and experiment. But with increasing beam energy there is an increasing discrepancy between the experimental and calculated data only for the first three detector plates $(Z=0,123$, and $254 \mathrm{~mm})$.
Such a discrepancy in backward direction from beam path in target is also observed for samples at $\mathrm{R}=4 \mathrm{~cm}$ and $12 \mathrm{~cm}$.
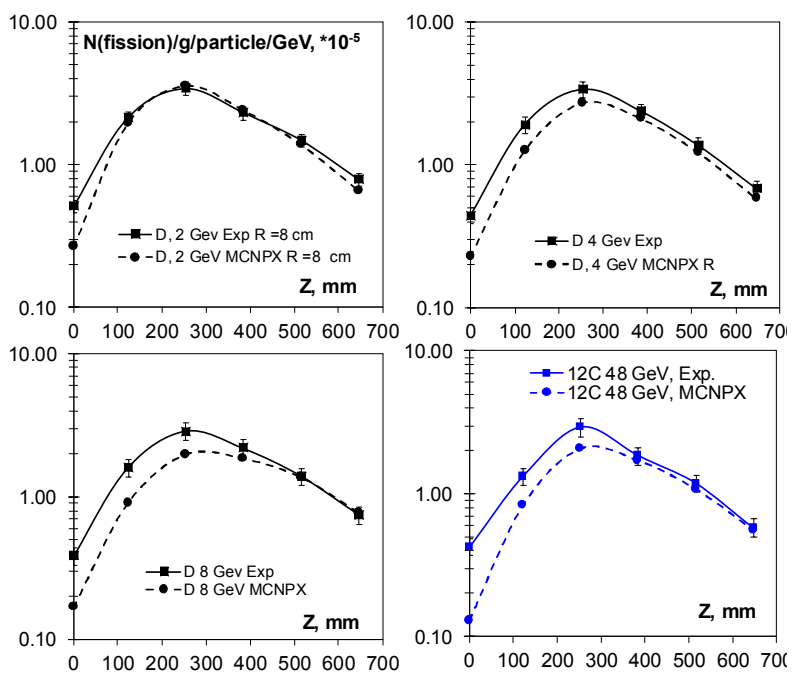

Fig. 5. Axial distributions of ${ }^{\text {nat }} U$ fission rates for samples at radial distances of $R=8 \mathrm{~cm}$. Experimental and Monte Carlo calculation

\section{2. ${ }^{59} \mathrm{Co}(n, x)$ REACTION RATES}

The spatial distribution of particle fluences in the extended uranium target ("Quinta" assembly) irradiated by $0.66 \mathrm{GeV}$ proton, 1, 2, $4 \mathrm{AGeV}$ deuteron and 2, $4 \mathrm{AGeV}$ carbon beams is studied by analyzing the accumulation rates of the isotopes with different threshold energy $\left(\mathrm{E}_{\mathrm{th}}\right)$ in ${ }^{59} \mathrm{Co}$ samples. The accumulation rates for the following isotopes: ${ }^{60} \mathrm{Co}\left(\mathrm{E}_{\text {th }} \approx 0 \mathrm{MeV}\right),{ }^{59} \mathrm{Fe}\left(\mathrm{E}_{\text {th }} \approx 3 \mathrm{MeV}\right)$, ${ }^{58} \mathrm{Co}\left(\mathrm{E}_{\mathrm{th}} \approx 10 \mathrm{MeV}\right),{ }^{57} \mathrm{Co}\left(\mathrm{E}_{\mathrm{th}} \approx 20 \mathrm{MeV}\right),{ }^{56} \mathrm{Co}\left(\mathrm{E}_{\mathrm{th}} \approx\right.$ $32 \mathrm{MeV}),{ }^{47} \mathrm{Sc}\left(\mathrm{E}_{\mathrm{th}} \approx 55 \mathrm{MeV}\right)$, and ${ }^{48} \mathrm{~V}\left(\mathrm{E}_{\mathrm{th}} \approx 70 \mathrm{MeV}\right)$ were measured $[7,10]$ using the HPGe spectrometers. It was found that neutron spectrum hardening in the uranium target of assembly "QUINTA" was observed with increasing of deuteron energy.

Fig. 6 shows dependence of reaction rates ratio

$$
R={ }^{59} \mathrm{Co}(n, x){ }^{48} \mathrm{~V} /{ }^{59} \mathrm{Co}(n, p){ }^{59} \mathrm{Fe}
$$

from deuteron energy (normalized to $2 \mathrm{GeV}$ ). This ratio does not include the errors from the beam intensity measurements. The maximum cross section of ${ }^{59} \mathrm{Fe}$ production take place at neutron energy $E_{n} \sim 13 \mathrm{MeV}$ (threshold energy $\mathrm{E}_{\text {th }} \approx 3 \mathrm{MeV}$ ), while the maximum cross section of ${ }^{48} \mathrm{~V}$ production take place at $\mathrm{E}_{\mathrm{n}} \sim 160 \mathrm{MeV}\left(\mathrm{E}_{\text {th }} \approx 70 \mathrm{MeV}\right)$ [22]. This reaction rates ratio increases with increasing of energy of primary deuteron beam.

As an example, Fig. 7 shows the axial distributions of reaction rate ${ }^{59} \mathrm{Co}(n, p){ }^{59} \mathrm{Fe}$ and ${ }^{59} \mathrm{Co}(n, x)^{48} \mathrm{~V}$ for deuterons with energy $E_{d}=2$ and $4 \mathrm{AGeV}$. The figure analysis shows, that the number of neutrons with energies above $100 \mathrm{MeV}$ increases with increasing of deuteron energy from 2 to $4 \mathrm{AGeV}$, but at the same time the number of neutrons with energies less than $30 \mathrm{MeV}$ decreases.

The experimental results were compared with the simulation performed [10] using the code Geant4. The simulations underestimate the production of isotopes with high threshold energy. The simulated values of the accumulation rates after $40 \mathrm{~cm}$ of uranium are $1.5 \ldots 2$ times lower than the experimental data. 
$48 \mathrm{~V} / 59 \mathrm{Fe}$

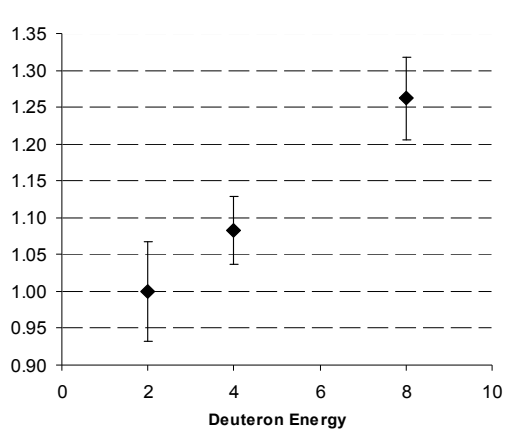

Fig. 6. Dependence of the reaction rates ratio ${ }^{59} \mathrm{Co}(n, x)^{48} V^{59} \mathrm{Co}(n, p){ }^{59} \mathrm{Fe}$ from deuteron energy $(\mathrm{GeV})$

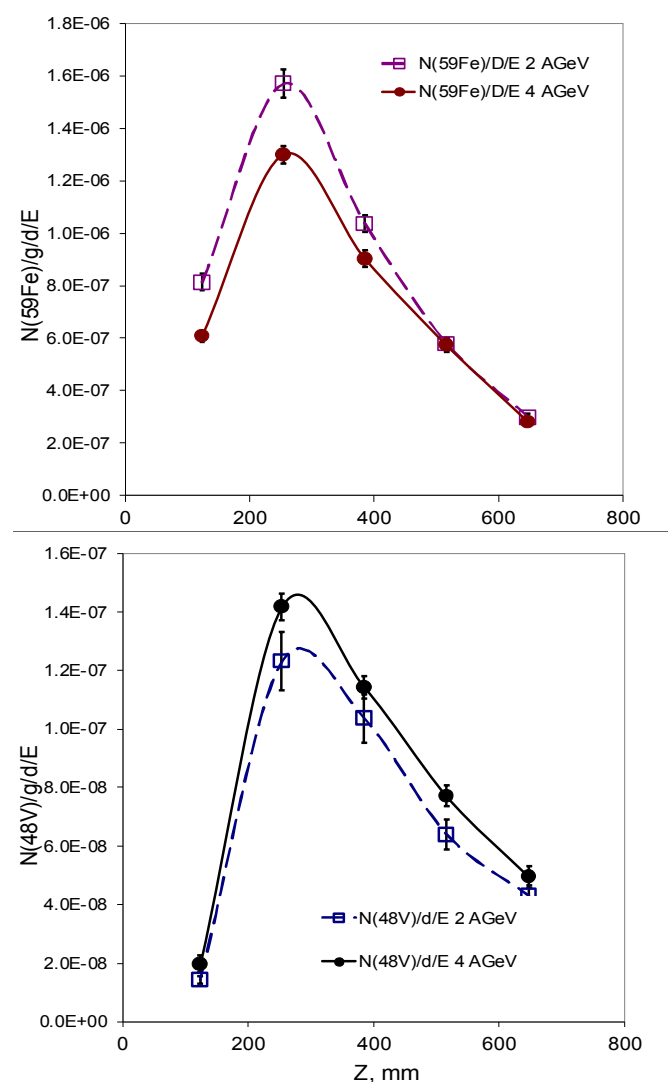

Fig. 7. Axial distribution of reaction rates

$\left.{ }^{59} \mathrm{Co}(n, p)\right)^{59} \mathrm{Fe}$ (up) and ${ }^{59} \mathrm{Co}(n, x){ }^{48} \mathrm{~V}$ (down) for deuteron energies 2 and $4 \mathrm{AGeV}$

The experimental data obtained with carbon beam show that the particle spectra become harder under irradiation by carbon in comparison with deuteron beam with the same energy per nucleon. For example, value $\mathrm{R}$ (1) for the $2 \mathrm{AGeV}$ carbon beam is 1.5-2 times greater than for the $2 \mathrm{AGeV}$ deuteron beam. The simulation does not reproduce correctly this effect.

The obtained results demonstrate that it is important to improve the simulation codes and to continue the experimental investigations with the extended target irradiated by light ion beams in an energy range greater than $2 \mathrm{GeV}$ per nucleon.

\subsection{NEUTRON-INDUCED TRANSMUTATION REACTIONS}

Transmutation reactions in the ${ }^{237} \mathrm{~Np},{ }^{238} \mathrm{Pu}$, and ${ }^{239} \mathrm{Pu}$ samples were investigated in the neutron field generated inside uranium target of assembly QUINTA under irradiation with 2, 4, and $8 \mathrm{GeV}$ deuteron beams [12].
The neutron-induced transmutation (fission) of the actinide samples was measured by methods of gammaray spectrometry with HPGe detectors. The experimental reaction rates of the respective residual nuclei have been divided by the cumulative fission yields taken from ENDF/B-VII.1 database. The most reliable results have been reached when selecting the data for neutron energy $\mathrm{E}_{\mathrm{n}}=500 \mathrm{keV}$. The other available energies had provided results with higher average deviation from the mean.

The following residual nuclei were identified in transmutation samples:

${ }^{237} \mathrm{~Np}$ samples: ${ }^{92} \mathrm{Sr},{ }^{97} \mathrm{Nb},{ }^{97} \mathrm{Zr},{ }^{132,133,135} \mathrm{I},{ }^{138} \mathrm{Cs},{ }^{142} \mathrm{La}$; ${ }^{238} \mathrm{Pu}$ samples: ${ }^{88} \mathrm{Kr},{ }^{91,92} \mathrm{Sr},{ }^{97} \mathrm{Nb},{ }^{97} \mathrm{Zr},{ }^{105} \mathrm{Rh},{ }^{105} \mathrm{Ru}$, ${ }^{129} \mathrm{Sb},{ }^{131,132,133,135} \mathrm{I},{ }^{142} \mathrm{La},{ }^{143} \mathrm{Ce}$;

${ }^{238} \mathrm{Pu}$ samples: ${ }^{87,88} \mathrm{Kr},{ }^{88} \mathrm{Rb},{ }^{91,92} \mathrm{Sr},{ }^{91 \mathrm{~m}} \mathrm{Y},{ }^{97} \mathrm{Nb},{ }^{97} \mathrm{Zr}$, ${ }^{103,105} \mathrm{Ru},{ }^{105} \mathrm{Rh},{ }^{127,128} \mathrm{Sn},{ }^{129,130} \mathrm{Sb},{ }^{138} \mathrm{Cs},{ }^{131 \mathrm{~m}, 133 \mathrm{~m}, 134} \mathrm{Te}$, ${ }^{139,140} \mathrm{Ba},{ }^{141,142} \mathrm{La},{ }^{143} \mathrm{Ce}$.

The average reaction rates for fission per unit beam energy, per one deuteron and per one atom are shown in Table 1.

Table 1

Average fission transmutation rates per unit beam energy

\begin{tabular}{|l|c|c|c|}
\hline Energy & $2 \mathrm{GeV}$ & $4 \mathrm{GeV}$ & $8 \mathrm{GeV}$ \\
\hline Sample & \multicolumn{3}{|c|}{ Transmutation rate $^{-1}$ atom $^{-1} \times$ deuteron $\left.^{-1} \times \mathrm{GeV}^{-1}\right)$} \\
\hline${ }^{237} \mathrm{~Np}$ & $0.9 \pm 0.1$ & $0.8 \pm 0.1$ & $0.7 \pm 0.1$ \\
\hline${ }^{238} \mathrm{Pu}$ & $2.4 \pm 0.3$ & $3.2 \pm 0.3$ & $1.8 \pm 0.3$ \\
\hline${ }^{239} \mathrm{Pu}$ & $4.3 \pm 0.5$ & $3.7 \pm 0.4$ & $4.0 \pm 0.4$ \\
\hline
\end{tabular}

The fission transmutation rate per unit beam energy remains stable within one standard deviation. The weighted mean over all the provided beam energies is equal to $(0.81 \pm 0.08) \cdot 10^{-26}, \quad(2.4 \pm 0.4) \cdot 10^{-26}$, and $(4.0 \pm 0.4) \cdot 10^{-26}$ (atom $\times$ deuteron $\left.\times \mathrm{GeV}^{-1}\right)$ in the case of ${ }^{237} \mathrm{~Np},{ }^{238} \mathrm{Pu}$, and ${ }^{239} \mathrm{Pu}$ samples, respectively.

Both the ${ }^{237} \mathrm{~Np}$ and ${ }^{239} \mathrm{Pu}$ isotopes are generated by the neutron induced reactions in ${ }^{238} \mathrm{U}$ target of QUINTA assembly:

$$
\begin{gathered}
{ }^{238} \mathrm{U}(n, 2 n){ }^{237} \mathrm{U}\left(\beta^{-} 6,75 d\right) \rightarrow{ }^{237} \mathrm{~Np} ; \\
{ }^{238} \mathrm{U}(n, \gamma){ }^{239} \mathrm{U}\left(\beta^{-} 23.5 m\right){ }^{239} \mathrm{~Np}\left(\beta^{-} 2,4 d\right) \rightarrow{ }^{239} \mathrm{Pu} .
\end{gathered}
$$

At the QUINTA target assembly, the production rate in ${ }^{238} \mathrm{U}$ target and transmutation rate of the investigated actinides can be studied simultaneously.

The data in Table 2 show a ratio of ${ }^{239} \mathrm{Pu}$ transmutation via fission to ${ }^{239} \mathrm{Pu}$ production through the ${ }^{238} \mathrm{U}(\mathrm{n}, \gamma){ }^{239} \mathrm{U}$ reaction.

Table 2

Ratio of the ${ }^{239} \mathrm{Pu}$ transmutation to its production in ${ }^{238} \mathrm{U}$

\begin{tabular}{|c|c|c|c|}
\hline Beam energy & $2 \mathrm{GeV}$ & $4 \mathrm{GeV}$ & $8 \mathrm{GeV}$ \\
\hline Production of ${ }^{239} \mathrm{Pu}$ in ${ }^{238} \mathrm{U}\left(10^{-26}\right.$ atom $^{-1} \times$ deuteron $\left.^{-1}\right)$ \\
\hline & $1.5 \pm 0.2$ & $2.0 \pm 0.2$ & $4.2 \pm 0.4$ \\
\hline \multicolumn{4}{|c|}{ Ratio of the transmutation of ${ }^{239} \mathrm{Pu}$ via fission to the } \\
its production through the radiative capture in ${ }^{238} \mathrm{U}$ \\
\hline & $5.9 \pm 0.2$ & $7.5 \pm 0.2$ & $7.7 \pm 0.6$ \\
\hline
\end{tabular}

In the case of the $2 \mathrm{GeV}$ deuteron beam, the ${ }^{239} \mathrm{Pu}$ transmutation rate is six times its production in ${ }^{238} \mathrm{U}$. The ratio increases with deuteron energy. The ratio is 7.5 for the $4 \mathrm{GeV}$ deuteron beam and 7.7 for the $8 \mathrm{GeV}$ beam. This serves as the evidence of the transmutation potential of the uranium spallation target. 
For the purpose of validation of radiation transport programs, the experimental results were compared [12] with simulations by the MCNPX 2.7 [20] and MARS15 [25] code, see Table 3 . The neutron spectra were simulated by the Monte Carlo method at the location of actinide samples for QUINTA target geometry. ENDF/BVII database, intranuclear physical model INCL4, evaporation model ABLA and LAQGSM03.03 code were used.

Table 3

Comparison of the fission transmutation rate between experiment and calculation

\begin{tabular}{|c|c|c|c|}
\hline Energy & $2 \mathrm{GeV}$ & $4 \mathrm{GeV}$ & $8 \mathrm{GeV}$ \\
\hline Sample & \multicolumn{3}{|c|}{ Experiment/Calculation ratio MCNPX } \\
\hline${ }^{237} \mathrm{~Np}$ & $0.9 \pm 0.1$ & $0.9 \pm 0.1$ & $0.9 \pm 0.1$ \\
\hline${ }^{238} \mathrm{Pu}$ & $0.8 \pm 0.1$ & $1.1 \pm 0.1$ & $0.8 \pm 0.1$ \\
\hline${ }^{239} \mathrm{Pu}$ & $0.9 \pm 0.1$ & $1.0 \pm 0.1$ & $1.1 \pm 0.1$ \\
\hline Sample & \multicolumn{3}{|c|}{ Experiment/Calculation ratio MARS15 } \\
\hline${ }^{237} \mathrm{~Np}$ & $0.8 \pm 0.1$ & $0.9 \pm 0.1$ & $0.7 \pm 0.1$ \\
\hline${ }^{238} \mathrm{Pu}$ & $0.9 \pm 0.1$ & $1.4 \pm 0.1$ & $0.7 \pm 0.1$ \\
\hline${ }^{239} \mathrm{Pu}$ & $1.2 \pm 0.1$ & $1.3 \pm 0.1$ & $1.2 \pm 0.1$ \\
\hline
\end{tabular}

In general, a good agreement between the experimental and calculated reaction rates was found in the whole interval of provided beam energies for MCNPX 2.7 code employing the INCL4-ABLA event generator.

\subsection{ESTIMATION OF THE BEAM POWER GAIN}

The beam power gain (or energy gain) $G$ in the multiplying target is one of the all-important ADS characteristics, indicating its ability to produce energy.

The minimum beam power gain value $\mathrm{G}_{\min }$ required for the energy reproduction (grid power required to run the accelerator) for ADS with beam power $>3 \mathrm{MW}$ must be at least about 9. For more powerful beams $\left(\mathrm{P}_{\text {beam }}>10 \ldots 20 \mathrm{MW}\right)$, it is possible to ensure energy reproduction even at $\mathrm{G}_{\mathrm{min}} \approx 6 \ldots 7.5$ (our estimations [14]).

The beam power gain $G$ can be determined by the following expression:

$$
G=\left(E_{p}+n_{f} \cdot E_{f}\right) / E_{p},
$$

where $E_{p}$ is the accelerated particle energy $(\mathrm{GeV}), n_{f}$ is the number of uranium fissions in the uranium assembly per one accelerated particle, $E_{f}$ is the fission energy (0.197 GeV).

The beam power gain determined in this way approximately corresponds to the total heat release in the target assembly normalized per primary ion beam power. In this case, we assume that only a small fraction of the primary ion energy out of the extended uranium target with $\gamma$-quanta and $\pi^{0}$ mesons. On the other hand, we take into account only the basic heat release due to the uranium fission, without taking into account other possible exothermic reactions on the secondary particles.

In the series of experiments, the uranium fission rate spatial distributions inside the Quinta target were obtained for various primary beams: $0.66 \mathrm{GeV}$ protons, 1 , 2, 4, and $8 \mathrm{GeV}$ deuterons, and 24 and $48 \mathrm{GeV}$ carbon ions. The total numbers of fission obtained for the target assembly (TA) Quinta are shown in Table 4 per one accelerated particle and per beam power.
Total numbers of fission

\begin{tabular}{|l|c|c|}
\hline Beam, GeV & $\mathrm{N}_{\mathrm{f}} /$ ion & $\mathrm{N}_{\mathrm{f}} /$ ion $/ \mathrm{GeV}$ \\
\hline $\mathrm{p}(0.66)$ & $4.1 \pm 0.3$ & $6.2 \pm 0.5$ \\
\hline $\mathrm{D}(1)$ & $8.9 \pm 0.6$ & $8.9 \pm 0.6$ \\
\hline $\mathrm{D}(2)$ & $19 \pm 1$ & $9.7 \pm 0.6$ \\
\hline $\mathrm{D}(4)$ & $37 \pm 2$ & $9.2 \pm 0.5$ \\
\hline $\mathrm{D}(8)$ & $71 \pm 4$ & $8.9 \pm 0.5$ \\
\hline${ }^{12} \mathrm{C}(24)$ & $160 \pm 20$ & $6.7 \pm 0.9$ \\
\hline${ }^{12} \mathrm{C}(48)$ & $340 \pm 40$ & $7.1 \pm 0.8$ \\
\hline
\end{tabular}

For all primary beams the beam power gain values $G$ for TA Quinta were determined using the expression (1). The results are shown in Table 5. The beam power gain values are in range from 2 to 3 for all beams. The small values of $\mathrm{G}$ are explained by the insufficient dimensions of the uranium target used in the experiments, which leads to a large neutron leakage.

In paper [24] (R.G. Vasilkov et al.) for a large natural uranium target with a mass of about $3.5 \mathrm{t}$ (due to asymmetric beam input, the effective mass was about $7 \mathrm{t}$ ), the fission total number of $18.5 \pm 1.7$ per 1 proton with an energy of $0.66 \mathrm{GeV}$ was obtained. The corresponding beam power gain value is 6.5 . This is without considering the fissions (3-4 fissions) and a small neutron leakage of $10 \ldots 12 \%$. If taking into account 3 fissions in the central part of the target and neutron leakage of $11 \%$ we can obtain $\mathrm{G} \sim 8$.

Using these results from the paper [24], the beam power gain values for the TA Quinta were extrapolated [14] for a quasi-infinite uranium assembly in which all the generated neutrons are completely utilized (see the values $\mathrm{G}_{\infty}$ in the Table 5).

The estimated $G_{\infty}$ values satisfy the minimum requirements $\left(G_{\min }>7\right)$ for energy reproduction. At the same time, simulations for quasi-infinite targets give significantly lower beam power gain values. For example, simulation with the MARS15 code $(120 \mathrm{~cm}$ diameter uranium target with $110 \mathrm{~cm}$ length) gives the maximum beam power gain value $\sim 5.5$ for protons with an energy of $2 \ldots 4 \mathrm{GeV}$ [26].

Table 5

Beam power gains for assembly Quinta and corresponding estimations for quasi-infinite uranium target

\begin{tabular}{|c|c|c|}
\hline Beam (Energy, GeV) & G Quinta & $\mathrm{G}_{\infty}$ \\
\hline $\mathrm{p}(0.66)$ & 2.2 & - \\
\hline $\mathrm{D}(1)$ & 2.7 & 11 \\
\hline $\mathrm{D}(2)$ & 2.9 & 11.6 \\
\hline $\mathrm{D}(4)$ & 2.9 & 11.4 \\
\hline $\mathrm{D}(8)$ & 2.8 & 11 \\
\hline${ }^{12} \mathrm{C}(24)$ & 2.3 & 8.5 \\
\hline${ }^{12} \mathrm{C}(48)$ & 2.4 & 9 \\
\hline $\mathrm{p}(0.66)[1]$ & - & 8 \\
\hline
\end{tabular}

Simulation with the MCNPX 2.7e code for the quasi-infinite depleted uranium target with a mass of $\sim 21 \mathrm{t}$ (BURAN setup built in JINR, Dubna [28], Fig. 8), irradiated by protons and deuterons of 1, 6, $12 \mathrm{GeV}$, gives beam power gain about 4 [27]. 


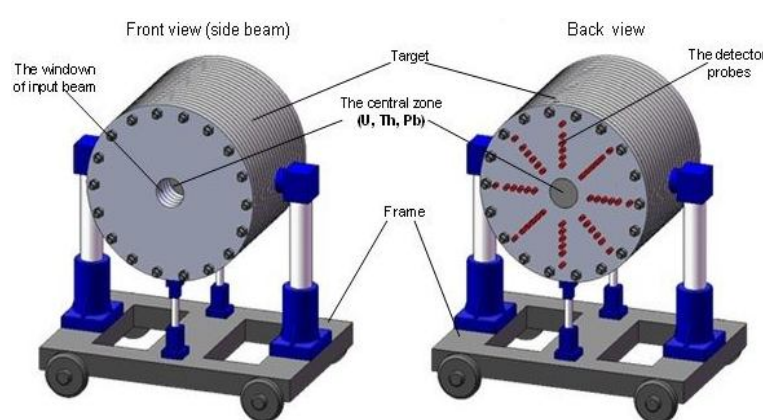

Fig. 8. Buran setup is a cylinder made from depleted uranium with a replaceable central zone. Uranium longitude of $1 \mathrm{~m}$ and $1.2 \mathrm{~m}$ in diameter. The cylinder is surrounded by $10 \mathrm{~cm}$ steel covering. The total mass

of uranium in the target assembly is about $21 \mathrm{t}$

Simulation with the FLUKA code [29] for BURAN setup, irradiated by protons and deuterons with the energy $1 \mathrm{GeV}$, gives beam power gain about 3.7 and 4.1 , respectively [28].

In terms of further research, first of all, it is necessary to verify experimental results [24] in the experiments with a large spallation target with the minimal neutron leakage.

\section{CONCLUSIONS}

It is shown that, within $14 \%$ of the experimental errors, the total number of fissions in the target normalized per unit of primary beam power is practically independent of the beam energy, and the total produced plutonium nuclei number in the target decreases with beam energy for both deuteron and carbon beams. As a consequence, the average spectral index also decreases, showing a hardening of the neutron spectrum inside the target with energy of the incident particles increasing.

The integral number of fission and capture reactions for carbon beams is smaller than for deuteron beams by $20 \ldots 25 \%$ at the same beam power and for beam energy $2 \ldots 4 \mathrm{GeV} /$ nucleon.

We have seen the large discrepancy between the experimental and calculated values of reaction rates in backward direction from beam path in target (first and second target section) for deuteron and carbon beams with 2 and $4 \mathrm{GeV} /$ nucleon.

Using activation cobalt detectors, it was found that neutron spectrum hardening in the uranium target of assembly "QUINTA" was observed with increasing of deuteron energy. For this type of particles and their energy range such experiments were performed for the first time. The experimental data obtained with carbon beam show that the particle spectra become harder under irradiation by carbon in comparison with deuteron beam with the same energy per nucleon. The simulation does not reproduce correctly this effect.

In the case of the $2 \mathrm{GeV}$ deuteron beam, the ${ }^{239} \mathrm{Pu}$ transmutation rate is six times its production in ${ }^{238} \mathrm{U}$. The ratio increases with deuteron energy. The ratio is 7.5 for the $4 \mathrm{GeV}$ deuteron beam and 7.7 for the $8 \mathrm{GeV}$ beam. This serves as the evidence of the transmutation potential of the uranium spallation target.

The estimated beam power gain values for quasiinfinite spallation target satisfy the minimum requirements $\left(G_{\min }>7\right)$ for energy reproduction. At the same time, simulations for quasi-infinite targets give significantly lower beam power gain values.

Some of obtained results demonstrate that it is important to improve the simulation codes and to continue the experimental investigations with the extended ADS target. According to the Monte Carlo simulation, almost $80 \%$ of all produced neutrons escape from the QUINTA target without any further interaction in uranium. Therefore, the basic principles of the relativistic nuclear technology must be verified in the experiments with a large, quasi-infinite spallation target with the minimal neutron leakage. Such experiment will be carried out at Dubna in the near future using the quasi-infinite uranium target BURAN.

\section{REFERENCES}

1. Web site of ORNL.http://neutrons.ornl.gov/ facilities/SNS/works.shtml

2. Web site of J-PARC.http://j-parc.jp/index-e.html

3. Y. Kadi, A. Herrera-Martinez. Multi-MW target development for EURISOL \& EUROTRANS European Organization for Nuclear Research // BENE Week. CERN, Switzerland, March 16-19, 2005.

4. V.I. Yurevich, R.M. Yakovlev, V.G. Lyapin. The study of neutron emission in the interaction of nuclei ${ }^{1} \mathrm{H},{ }^{2} \mathrm{H},{ }^{4} \mathrm{He},{ }^{12} \mathrm{C}$, with energy of $1 \ldots 2 \mathrm{AGeV}$ with lead nuclei // Nuclear Physics. 2006, v. 69, № 9, p. 1531-1543.

5. V.I. Yurevich, R.M. Yakovlev, R.G. Vasilkov, et al. Production and multiplication of neutrons in lead targets induced by protons above $1 \mathrm{GeV} / /$ Nuclear Instr. and Meth. in Phys. Research, A. 2006, № 562, p. 747-749.

6. A.A. Baldin, E.M. Belov, M.V. Galanin, et al. Relativistic Nuclear Technology (RNT) for Energy Production and Utilization of Spent Nuclear Fuel (SNF). The Results of First Experiments on Physical Justification of RNT // Particles and Nuclei, Letters. 2011, v. 8, Issue 6, p. 1007-1023.

7. M. Artyushenko, A. Baldin, A. Berlev, et al. Comparison of neutron-physical characteristics of uranium target of assembly "Quinta" irradiated by relativistic deuterons and ${ }^{12} \mathrm{C}$ nuclei // Problems of Atomic Science and Technology. Series "Nuclear Physics Investigations”. 2016, № 3, p. 74-79.

8. I. Adam, M.Yu. Artyushenko, A.A. Baldin, et al. The Study of Spatial Distributions of Neutron Capture and Fission Reactions in Massive Uranium Target Irradiated by Deuterons with Energies of $1 \ldots 8 \mathrm{GeV}$ ("Quinta" Setup): Preprint JINR. 2012, P1-2012147, Dubna.

9. M.Yu. Artyushenko, V.A. Voronko, K.V. Husak, et al. Investigation of the spatial and energy distributions of neutrons in the massive uranium target irradiated by deuterons with energy of $1 \ldots 8 \mathrm{GeV} / /$ Problems of Atomic Science and Technology. 2013, № 6, p. 170-174.

10. J. Adam, A.A. Baldin, M. Baznat, et al. Secondary particle distributions in an extended uranium target under irradiation by proton, deuteron, and carbon beams // Nuclear Instr. and Meth. In Phys. Res. A. 2017 , v. 872 , p. 87-92. 
11. L. Zavorka, J. Adam, M. Artyushenko, et al. Validation of Monte-Carlo simulation of neutron production in a spallation target // Annals of Nuclear Energy. 2015, v. 80, p. 178-187.

12. L. Zavorka, J. Adam, A. Baldin, et al. Neutroninduced transmutation in ${ }^{237} \mathrm{~Np},{ }^{238} \mathrm{Pu}$ and ${ }^{239} \mathrm{Pu}$ at the massive natural uranium spallation target // Nuclear Instr. and Meth. in Phys. Res. 2015, B 349, p. 31-38.

13. S.R. Hashemi-Nezhad, N.L. Asquith, V.A. Voronko, V.V. Sotnikov, Alina Zhadan, et al. Transmutation of uranium and thorium in the particle field of the Quinta sub-critical assembly // Nuclear Instr. and Meth. in Phys. Res. 2018, A 883, p. 96-114.

14. V.A. Voronko, A.A. Zhadan, V.V. Sotnikov, et al. Estimation of the beam power gain for deepsubcritical uranium assembly Quinta under relativistic proton, deuteron and carbon nuclei irradiation // Problems of Atomic Science and Technology. Series "Nuclear Physics Investigations”. 2018, № 3, p. 183-187.

15. A. Zhadan, V.V. Sotnikov, V.A. Voronko, S.I. Tyutyunnikov, P. Zhivkov. Spatial Distributions of ${ }^{\text {nat }} \mathrm{U}(\mathrm{n}, \mathrm{f}),{ }^{238} \mathrm{U}(\mathrm{n}, \mathrm{g})$ Reaction Rates in Spallation Neutron Fields Produced by Deuterons and ${ }^{12} \mathrm{C}$ Ions on the Massive Uranium Target // IPAC 2017 May 14-19, 2017, Copenhagen, Denmark. AIP Conference Proceedings THPVA129.

16. A. Zhadan, V. Sotnikov, J. Adam, et al. Experimental Studies of the Medical Radioisotopes Production // Carpathian Summer School of Physics, Sinaia, Romania, June 26-July 9, 2016. AIP Conference Proceedings 1852, 080013 (2017); https: //doi.org/10.1063/ 1.4984887.

17. M.Yu. Artyushenko, V.A. Voronko, K.V. Gusak, et al. Measuring deuteron beam parameters with solidstate track detectors in experiments with the QUINTA target assembly // Physics of Particles and Nuclei Letters. 2013, v. 10(6), p. 544-548.

18. A.A. Safronava, A.A. Patapenka, V.V. Sotnikovet al. Monitoring of $\mathrm{GeV}$ Deuteron Beam Parameters in ADS Experiments at the Nuclotron (JINR, Dubna) // Proceedings of DIPAC 2011, May 2011, Hamburg, Germany, p. 530-532. TUPD94.
19. M.Yu. Artyushenko, V.A. Voronko, Yu.T. Petrusenko, et al. Monitoring of high energy deuteron beams in the experiments with massive targets // Problems of Atomic Science and Technology. Series "Nuclear Physics Investigations”. 2014, № 3, p. 186-189.

20. D.B. Pelowitz. MCNPX User's Manual, Version 2.7.0. Los Alamos National Laboratory report LACP-11-00438, 2011.

21. M.B. Chadwick, M. Herman, P. Oblo־zinsky, et al. "ENDF/B-VII.1 Nuclear Data for Science and Technology: Cross Sections, Covariances, Fission Product Yields and Decay Data // Nuclear Data Sheets. 2011, v. 112, p. 2887-2996.

22. A. Koning et al. TENDL-2014: TALYS-based evaluated nuclear data library, www.talys.eu/tendl2014.html.

23. S. Agostinelli et al. Geant4 - a simulation toolkit // Nuclear Instr. and Meth. 2003, A 506, p. 250-303.

24. R.G. Vasil'kov, V.I. Gol'danskii, B.A. Pimenov, et al. Neutron multiplication in uranium bombarded with 300...660 MeV protons // Atomic Energy (New York); 1978, v. 44 (4), p. 377-384; https://doi.org/ 10.1007/BF01124414.

25. N.V. Mokhov et al. Technical Report FERMILABCONF-12-635-APC, 2012.

26. V.S. Pronskich, N.V. Mokhov, I. Novitski, S.I. Tyutyunnikov. Energy Production Demonstrator and Material Testing Station optimization for Megawatt proton beams // Annals of Nuclear Energy. 2017, v. 109, p. 692-697.

27. P. Zhivkov, W. Furman, and Ch. Stoyanov. Calculation of ADS with deep subcritical uranium active core - comparison with experiments and predictions // Journal of Physics: Conference Series 533. 2014, p. 012053.

28. V. Bukhal, K. Husak, I. Zhuk, et al. Neutronphysical characteristics of a system of Quasi-infinite depleted uranium blanket - particle Accelerator. Monte Carlo simulation // Problems of Atomic Science and Technology. Series "Nuclear Physics Investigations”. 2019, № 6, p. 181-184.

29. A. Ferrari. FLUKA: a multi-particle transport code / A. Ferrari, P.R. Sala, A. Fasso', and J. Ranft, CERN2005-10 (2005), INFN/TC_05/11, SLAC-R-773.

Article received 21.02.2020

ЭКСПЕРИМЕНТАЛЬНЫЕ ИССЛЕДОВАНИЯ ЯДЕРНО-ФИЗИЧЕСКИХ ХАРАКТЕРИСТИК ПРОТЯЖЕННОЙ УРАНОВОЙ МИШЕНИ, ОБЛУЧАЕМОЙ РЕЛЯТИВИСТСКИМИ ПРОТОНАМИ, ДЕЙТРОНАМИ И ЯДРАМИ ${ }^{12} \mathrm{C}$ А.А. Жадан, В.В. Сотников, В.А. Воронко, А.А. Балдин, С.И. Тютюнников, О.В. Бухал, К.В. Гусак, И.В. Жук,

\section{П. Живков}

В 2011-2017 гг. в рамках Международной коллаборации «Энергия и трансмутация РАО» была проведена серия экспериментальных исследований на глубоко подкритической урановой сборке «КВИНТА». Массивная урановая мишень $\left(512\right.$ кг $\left.{ }^{\text {nat }} \mathrm{U}\right)$ сборки облучалась 0,66 ГэВ протонами, дейтронами и ядрами ${ }^{12} \mathrm{C}(1 \ldots 4$ ГэВ/нукл.) от ускорителей Фазотрон и Нуклотрон (ОИЯИ, г. Дубна). Представлены основные результаты экспериментальных исследований, выполненных при участии харьковской группы коллаборации.

ЕКСПЕРИМЕНТАЛЬНІ ДОСЛІДЖЕННЯ ЯДЕРНО-ФІЗИЧНИХ ХАРАКТЕРИСТИК ПРОТЯЖНОЇ УРАНОВОЇ МІШЕНІ, ОПРОМІНЮВАНОЇ РЕЛЯТИВІСТСЬКИМИ ПРОТОНАМИ, ДЕЙТРОНАМИ ТА ЯДРАМИ ${ }^{12} \mathrm{C}$ А.О. Жадан, В.В. Сотников, В.О. Воронко, А.О. Балдін, С.І. Тютюнников, О.В. Бухал, К.В. Гусак, І.В. Жук, П. Живков

У 2011-2017 рр. у рамках Міжнародної колаборації «Енергія і трансмутація РАВ» було проведено серію експериментальних досліджень на глибоко підкритичній урановій збірці «КВІНТА». Масивна уранова мішень $\left(512\right.$ кг ${ }^{\text {nat } U) ~}{ }^{3 б і р к и ~}$ опромінювалася 0,66 ГеВ протонами, дейтронами і ядрами ${ }^{12} \mathrm{C}(1 \ldots 4$ ГеВ/нукл.) від прискорювачів Фазотрон і Нуклотрон (ОІЯД, м. Дубна). Наведено основні результати експериментальних досліджень, які було виконано за участю харківської групи колаборації. 